\title{
La lectura que da vida: elogio del artículo'
}

\author{
Reading that Gives Life:Article Praise \\ NONIBENEGAS \\ Asociación Genialogías \\ Argentina \\ nonibenegas@gmail.com
}

(Recibido: 22-O6-20I8; aceptado: 25-06-20I8)

Creo que al principio fue el sonido. O la pronunciación, para ser precisa. Ese mascullar y repetir soniquetes, y jugar en la punta de los labios o entre dientes con el caramelo crujiente de la palabra. En la escuela, debe haber empezado por mi mamá me mima, o amasa la masa, pero si quiero recordar los armónicos, surgen poetas de los que nadie se acuerda hoy, cuyos versos aun repiquetean: música porque si, música vana, como la vana música del grillo, mi corazón eglógico y sencillo, se ha despertado grillo esta mañana. $\mathrm{O}$ : Caballito criollo del galope corto, del aliento largo y el instinto fiel... Nalé Roxlo y Belisario Roldán eran dos vates de la época en Argentina, que aprendíamos en la escuela, y cuyo destino literario ya estaba escrito al final del poema del segundo: Caballito criollo que pasó y sefue. Es decir, no son, o no fueron exportables. Y claro, cuando volvías a casa, allí estaba el volumen todo en piel como un balón pequeño y oscuro encaramado a la biblioteca, que al abrirlo, era como esas frutas tropicales, todo seda por dentro. Y al cerrarlo, brillaban en la portada tres hilos de oro seguidos por unos guarismos pequeñitos con un nombre -deletreado y acariciado con fruición- que reproducían la firma del autor: Federico García Lorca. Entonces, leías: vuelan en la araña gris los siete pájaros del prisma, o verde que te quiero verde... eran cosas mágicas, casi conjuros. Y otras, puro atrevimiento, en medio de canciones en apariencia inocentes: el jovencito se olvidaba, eran las 10 de la mañana, él se sintió balcón y torre... que aludía a un suicidio, a una edad en la que no piensas más que en entornar la puerta, para ver que hay detrás. Y que casaba tan bien con este otro pareado: La rosa no buscaba la rosa, inmóvil por el cielo, buscaba otra cosa. $O$ la duda de la identidad: Entre los juncos y la baja tarde, ; qué raro que me llame Federico!

\footnotetext{
${ }^{\text {I }}$ Para citar este artículo: Benegas, Noni (20I8). La Lectura que da vida: elogia del artículo. Álabe 18. [www.revistaalabe.com] DOI: IO.I5645/Alabe20I8.I8.9
} 
Pero leer, lo que se dice leer literalmente como en la infancia, había libros que me reservaba para eso. Párrafos enteros, o deletreando, no había caso; sólo entendía la espuma, el vaivén de la ola, la masa de palabras que subía y bajaba rítmicamente, y acompasaba un decir abstruso, oscuro, pero invocativo, como las metáforas lorquianas. El libro tenía título de poema: Crítica de la razón pura, y del autor, Kant, gustaba recordar su rutina diaria y el pañuelo que dejaba en una determinada esquina del escritorio, o la puntualidad de acero, que hacía que las vecinas corrigieran sus relojes cuando él pasaba durante su paseo matutino. Como si la razón pura fuera un mecanismo de relojería que antes que la frase, compusiera al autor, para que paso a paso desgranara el texto como el reloj las horas. Pero ni siquiera era original esa música, sino que estaba versionada, traductor por medio, del alemán.

La que si me abrió la imaginación a un tipo de comprensión más alta que fundía el sonido y el sentido, fue la escucha casual de la Noche Oscura del Alma, en boca de un locutor por la radio, y recuerdo que se hizo de noche aunque era de día. En una noche oscura, con ansias en amores inflamada, salí sin ser notada, estando ya mi casa sosegada... Creo que ahí cuajó mi vocación. Cuando comprobé que Juan de la Cruz podía crear un universo paralelo, enormemente sugestivo, con pocas palabras combinadas de manera encantatoria tal como Mandrake, el mago del tebeo, con hipnóticos gestos de las manos.

La adolescencia fue una búsqueda constante de revelaciones. A los I5 descubrí en una revista el poema de una poeta de Buenos Aires, Elva de Lóizaga, que anticipaba rasgos de mi vida futura: Cuando tu propia calle te resulte extraña, y hasta el muro encalado de tu casa te recuerde una ciudad española, que nunca has visto pero que no es la tuya.... Nombraba la extrañeza de las cosas cercanas, y evocaba la particular nostalgia de un recuerdo que se ignora -y a la vez presagia el porvenir: lo que tendré y perderé-, que Freud caracterizó como melancolía.

La prosa tenía sus caminos y se abrió paso hacia mi a través de la conversación con un tal Michel de Montaigne, que charlaba un poco de todo, y se detenía en temas escabrosos con total naturalidad. Así, la vida de Mesalina, en referencia al deseo femenino -no menos voraz, en su opinión, que el masculino- aun con ser un retrato extremo, abría un territorio hasta entonces escamoteado por la mayoría de escritores.

Otro extraño libro, ni novela ni filosofía, sino ensayo concebido como tanteo, intento, reconocimiento de si mismo en la estela del francés, fue el de título aciago: "La tumba sin sosiego", y contenido encantador. Mitad sueño, mitad realidad, Cyril Connolly divagaba tras ser abandonado por un París desierto y veraniego, con citas (de autores favoritos) y comentarios (de un diario propio) sobre el amor y la literatura. La mujer aparecía evasiva, un punto alada con su veloz sandalia, al igual que la amada de paso ligero del Pavese poeta, para la cual: no hay palabras que puedan poseerte o guardarte. Así se insinuaban las mujeres en los relatos masculinos: libérrimas cuando no lujuriosas, o fugitivas e indecibles. Eran roles posibles, pero aun ficticios; me faltaba conocerlas de primera mano. 
Apareció, entonces, una jovencísima heroína contada por una autora de su misma edad -¿autobiografía?- en un escenario que remedaba el de Connolly: París estival y existencialista, con la libertad sexual de una romana del imperio, que hubiera leído todos los libros y sospechara que la carne es triste. Buenos días tristeza, de Françoise Sagan cerró una época e inauguró otra con gesto rotundo. En vez de dirigir sus baterías contra si misma como terminara haciendo Lóizaga, al igual que Alfonsina Storni o Alejandra Pizarnik, la protagonista se revolvía contra una madrastra incómoda que pretendía recortar sus privilegios. Violaba el dogma de la mujer perfecta -la perfecta casada-, o angelical -el ángel del hogar-, y podía actuar en defensa propia al ver amenazada su libertad.

En paralelo, el cine empezó a entregar heroínas de la llamada nouvelle vague, entre las que encontré el personaje ideal con el cual me identificaría. La Mónica Vitti de "La noche" o "El eclipse" no era una diva a merced de una cámara extasiada o violenta, sino una mujer ante una lente sensible -la de Antonioni- que adoptaba su punto de vista. Ella era testigo de un mundo alienado o incomunicado -el problema era el mismo en literatura: la sospecha de que las palabras estuvieran diciendo lo que queríamos decir- $\mathrm{y}$ ejemplificaba el estado de perplejidad en que me encontraba.

No tardé en descubrir "El segundo sexo" de Simone de Beauvoir, y "La mística de la femineidad" de Betty Friedan, que buceaban en la nada que nos rodeaba, y explicaban las causas de la deriva absurda en que vivíamos. Pero no fue hasta la lectura de "Política Sexual", de Kate Millet y el "Speculum”, de Luce Irigaray, que muchas de mi generación sintonizamos con unas problemáticas que nos tocaban de lleno. Su repercusión internacional fue decisiva para dotar de sentido a la segunda ola feminista, la de los '7o. Sin embargo, quiero recordar aquí a dos autoras menos connotadas de nuestra lengua, y a sendos artículos dentro de su amplia bibliografía, porque me enseñaron a leer de otra manera. Me refiero a "Las tretas del débil", de Josefina Ludmer, y a "Dos lecturas del cisne: Rubén Darío y Delmira Agustini, de Silvia Molloy. Ambas argentinas, con una importante obra ensayística, construida en gran parte en universidades de primer orden en Estados Unidos, a lo que se suma en el caso de Molloy, una atrayente incursión en la ficción y las memorias.

Tengo para mi, que el tratamiento que dan al artículo rebasa lo que una espera de éste. Conciso, argumentado, punzante, podría decirse con un símil que es al ensayo lo que el cuento a la novela. En "Las tretas...", Ludmer constata los continuos cambios de máscara y género de Sor Juana Inés de la Cruz que se revelaron eficaces para eludir la censura de su tiempo, así como las estrategias para hablar desde una posición subalterna, sin estar autorizada a ello. En "Dos lecturas del cisne...." Molloy desvela el aniñamiento o infantilización que la crítica construyó alrededor de la imagen de la poeta uruguaya, con el fin de desviar la atención del erotismo que inflama su trabajo. Pero, también, para rebajar el ardor de una mujer que desea y se atreve a decir su deseo. Hacia el final, Molloy sugiere leer el "Nocturno" de Agustini como respuesta violenta e iconoclasta a Darío, de 
cuya poesía se separaba para alzar la propia, y descubrir así la clave del verdadero diálogo que se entabló entre ellos: más allá del Maestro y la Niña, entre dos escritores y su obra.

La sagacidad con que las ensayistas sacan a luz los recursos retóricos de una y otra para la consecución de sus fines, me adiestraron para buscar en los textos los secretos, o enigmas desconocidos incluso para sus autores. El modo en que la monja y la poetisa uruguaya enmiendan la letra a sus maestros o superiores entre líneas -“di tu verdad, pero dila al sesgo", recomendaba Emily Dickinson- me permitió descubrir hasta qué punto mucho de lo que había leído con total inocencia, cobraba un sentido amargo pero real.

Doy un ejemplo de todos conocido. El de aquel amable marqués de Santillana, que venía a caballo desde el fondo de los tiempos y farfullaba: moza tan fermosa, non vi en la frontera, como aquesta vaquera de la Finojosa....para mi deleite. Pero es obvio que no entendí el sentido total del poema, ni nadie se preocupó de aclarármelo en la escuela, porque lo que ahí se dirime es el derecho de pernada. Nada menos que el privilegio feudal del "ius primae noctis" por el que los nobles tenían potestad de pasar la noche de bodas con la mujer de sus vasallos. ¿Pierde con esto gracia el verso del antiguo Señor? ¿Dejaremos de pronunciarlo con placer? No lo sé, pero es bueno que estemos avisados. 